\title{
Development of an optimal relief method for the palatal plate by stress analysis
}

\author{
Tomoko Mukai*, Yuji Sato, Osamu Shimodaira, Junichi Furuya, Akio Isobe and Tomoka Omori
}

\begin{abstract}
Background: Plate dentures cannot be easily modified after fabrication; therefore, the sites and magnitude of relief must be effectively assessed at the time of fabrication. However, a considerable variation exists in the magnitude of optimal relief and relief range, and there are no guidelines that present these clearly, leading the dentists to decide subjectively. Thus, this study aims to develop an optimal relief method to improve the stress bearing capacity of the palatal mucosa.

Methods: The objective of this study, namely, the borderline, was set in steps. A three-dimensional finite element model for the pseudopalatal plate was created and used to evaluate the changes in stress distribution in the palatal mucosa due to the selective relief of stresses above the borderline. The resulting data were used to develop the optimal relief method.

Results: In the relief model with a borderline of $0.04 \mathrm{MPa}$ or higher, the distribution volume at which a high stress of $0.20 \mathrm{MPa}$ or higher is generated was approximately $800 \%$ of that with the no-relief model, and in the relief model with a borderline of $0.06 \mathrm{MPa}$ or higher, the respective ratio was approximately $280 \%$. On the other hand, the relief models with a borderline of $0.14 \mathrm{MPa}$ or higher were approximately $60 \%$. In the mid-palatal relief model, the distribution volume at which a stress of $0.20 \mathrm{MPa}$ or higher was generated was $180 \%$ of that in the relief model.
\end{abstract}

Conclusions: The supportive strength of plates can be increased by selectively applying optimal relief rather than standard relief, allowing for easier and more effective plate-denture treatment.

Keywords: Palatal mucosa, Relief, Simulation, Three-dimensional finite element analysis, Stress distribution, Borderline

\section{Background}

With the aging population in Japan, the demand for removable denture prosthetics is increasing [1]. Highquality plate-denture treatment is linked to an increased quality of life for patients. For plate-denture treatment, an objective evaluation of the properties of the denturesupporting mucosa is important.

Recently, plate dentures with frameworks of cobaltchromium alloy and zirconia have been widely used for their increased durability and comfort while in use $[2,3]$.

*Correspondence: t.mukai@dent.showa-u.ac.jp

Department of Geriatric Dentistry, School of Dentistry, Showa University,

Ota, Tokyo 145-8515, Japan
However, after the fabrication of these dentures, it is difficult to modify them by adjusting; therefore, it is essential to sufficiently assess the sites and magnitude of relief at the time of fabrication. In practice, in connection with complete denture treatment in the past, as a part of denture design, relief is provided in the mid-palatal area. This relief is an important means of preventing pain due to the denture plate in the region of mucosal thinning, ensuring denture stability, and preventing denture damage, as well as preventing compression injury to the nerves and blood vessels $[4,5]$. However, a considerable variation exists in the magnitude of optimal relief and relief range, and no guidelines are available that present these clearly, leading the dentists to decide subjectively. 
To optimize denture design for individual patients, a system has been developed by fitting a strain gauge to an ultrasonic thickness gauge so that changes in load and mucosal thickness causing pain are measured simultaneously [6]. Further, the relationships between the properties of the denture-supporting mucosa (thickness and elasticity) and the pain threshold (pressure, degree of subsidence, and compression rate) in dentate and edentulous persons have been analyzed [7, 8]. In addition, to apply this system clinically, a maxillary-palate-shaped device has been developed for the simultaneous measurement of bite force and palatal mucosal subsidence at the time of pain onset in dentate persons. By using this device, the relationships between bite force and palatal mucosal subsidence in dentate persons were analyzed simultaneously, and the effects of palatal relief on palatal-mucosal-supporting strength were clarified [9]. Palatal mucosal stress analysis in a simulation based on three-dimensional (3D) finite element analysis (FEA) is effective for the objective evaluation of various types of denture-supporting mucosa [10].

In this study, the borderline was defined as the cutoff value of the stress generated in the palatal mucosa for relief; the borderline was set in steps in this study. The changes in stress distribution in the palatal mucosa due to the selective relief of stresses above the borderline were evaluated via a $3 \mathrm{D}$ finite element simulation. The purpose of this study was to develop an optimal relief method to improve the stress bearing capacity of the palatal mucosa.

\section{Methods}

\section{Subject and region of interest}

The subject was a dentate person with no abnormality in the palatal mucosa or presence of a marked tori. This person has participated in previous studies in which mucosal elasticity and thickness were measured. Further, a 3D finite element model was prepared. Similar to previous studies, the region of interest was defined as the palatal mucosa extending on the maxilla from a position mesial to the first molars on the left and right side to a position distal to the second molars on the left and right $[9,10]$. This study was conducted in accordance with the principles of the Declaration of Helsinki. The informed consent form was approved by the Ethics Committee of Showa University (approval number 2014-036).

\section{Establishment of 3D finite element models}

\section{(1) Establishment of the pseudopalatal plate model}

The pseudopalatal plate of the device for the simultaneous measurement of the palatal region was prepared using X-radiographically observable scanning resin, and computed tomography was performed. A 3D finite element model for the pseudopalatal plate was created from the computed tomography data obtained using a 3D FEA software (Mechanical Finder ${ }^{\circledR}$; Research Center of Computational Mechanics, Inc., Tokyo, Japan; Fig. 1). This was referred to as the no-relief model [10].

(2) Relief settings

(1) Setting the borderline for the stress

In a previous study, the pain generating bite force was measured as $111 \mathrm{~N}$ [10]. This force was applied to the center of the no-relief model, and the value of stress thus generated in the palatal mucosal model at that time, $0.02 \mathrm{MPa}$, was set as one end of the range for bite force in the simulation, with $0.20 \mathrm{MPa}$ as the other end. In other words, the bite forces were set as 0.04, 0.06, 0.08, 0.10, and $0.14 \mathrm{MPa}$. The stress generation ranges at each bite force or higher were considered to be the target ranges for relief (Fig. 2).

(2) Relief in ranges within which stress is generated at borderline or higher

Based on the range in the no-relief model where stresses above the borderline were generated, this model was trimmed. Then, a relief of $0.25 \mathrm{~mm}$ [11] was applied to this trimmed area to create the outline of the pseudopalatal floor model with relief. Each of the resulting model was categorized as the $0.04 \mathrm{MPa}$ or higher, $0.06 \mathrm{MPa}$ or higher, $0.08 \mathrm{MPa}$ or higher, $0.10 \mathrm{MPa}$ or higher, and 0.14 MPa or higher relief model (Fig. 2).

(3) Single relief for the general mid-palatal area

Based on the no-relief model, relief was applied to breadths of 10 and $0.25 \mathrm{~mm}$ in the maxillary mid-palatal area, thereby providing a single relief to the maxillary mid-palatal area of the external form of the pseudopalatal plate model. This is referred to as the mid-palatal relief model (Fig. 2).

\section{Setting the external form of the palatal mucosa model}

The mucosal surface in the pseudopalatal plate model was divided into 14 segments consistent with the measurement sites, and the measured palatal mucosal thickness was added as an element. In addition, the segments were edited to ensure smoothness [10].

\section{Mesh formation}

To ensure consistency with previous studies [10], tetrahedral meshing with a size of $0.5 \mathrm{~mm}$ was chosen in this study. The mesh was created using the automatic creation function of the Mechanical Finder ${ }^{\circledR}$ software with 88,951 nodes and 475,962 elements in total. In addition, both the pseudopalatal plate model and the palatal mucosa model were considered to be homogeneous and isotropic linear elastic structures. 
(A)

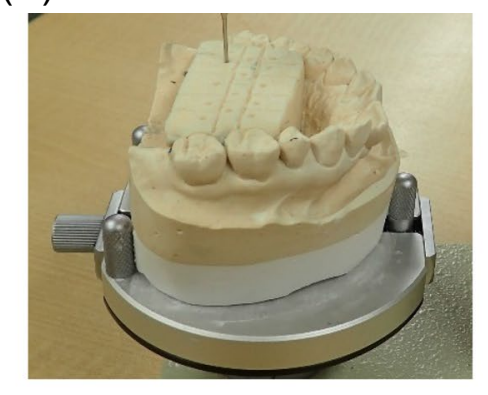

(C)

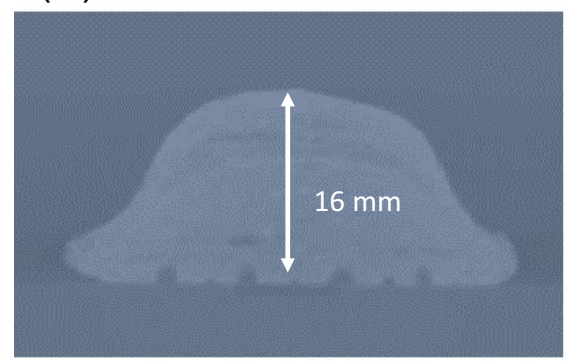

(B)
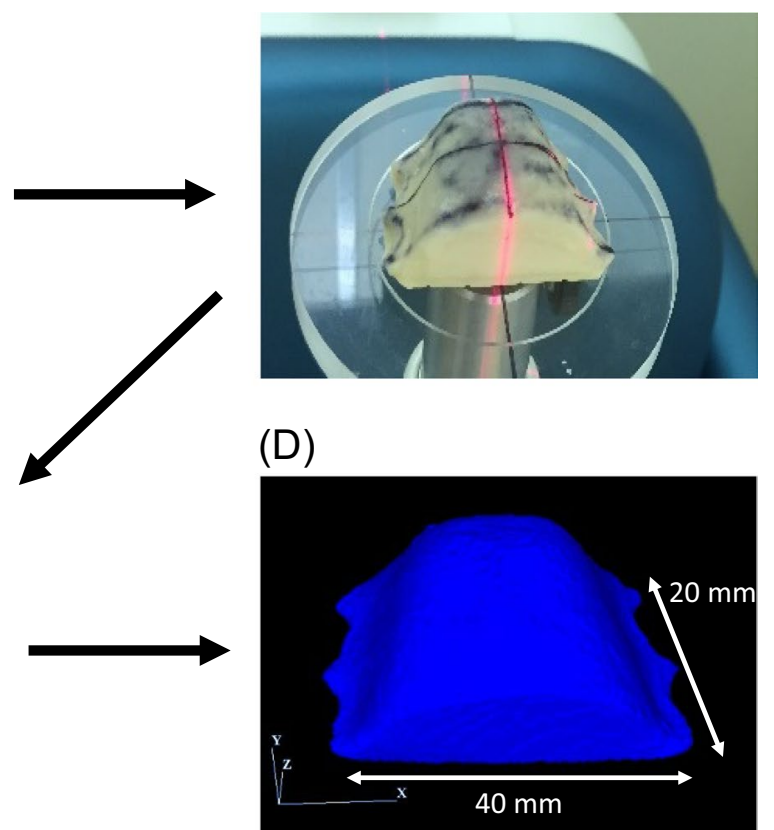

Fig. 1 Constructing the three-dimensional finite element model. A Pseudopalatal plate using scanning resin; B CT imaging; C captured by 3D-FEA software; $\mathbf{D}$ three-dimensional finite element model of the pseudopalatal plate

\section{Analysis conditions}

\section{(1) Setting physical values}

The physical properties of the resin in a humid environment were evaluated using a pseudopalatal plate model. The elasticity was assumed to be $2650 \mathrm{MPa}$ [12], and the Poisson's ratio was 0.3 [13]. The elasticity calculated from the measurements of the subject was applied to the palatal mucosa model [10].

(2) Loading conditions

The loading was vertical onto the center of the pseudopalatal plate. With respect to the load, when the subject developed pain, the bite force was $111 \mathrm{~N}$ [10] (Fig. 3).

\section{$0.02 \mathrm{MPa}$}

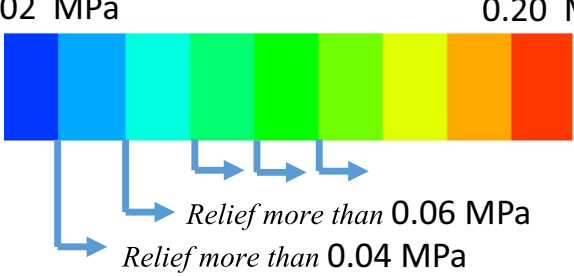

(B)

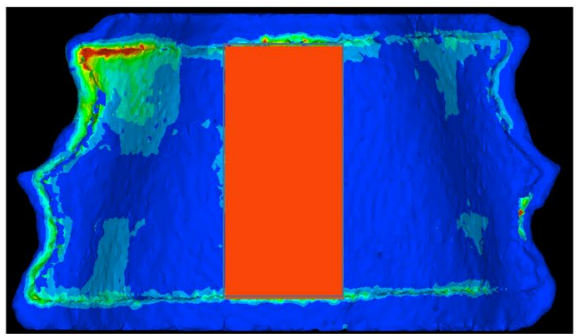

(A)

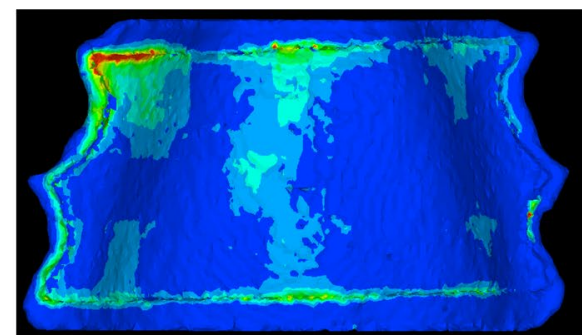

(C)

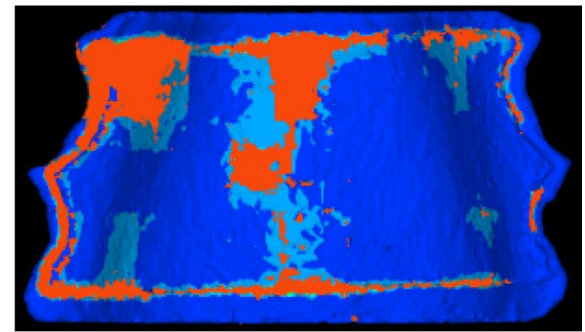

Fig. 2 Relief setting. A No relief; B mid-palate relief; $\mathbf{C}$ relief more than $0.06 \mathrm{MPa}$ 


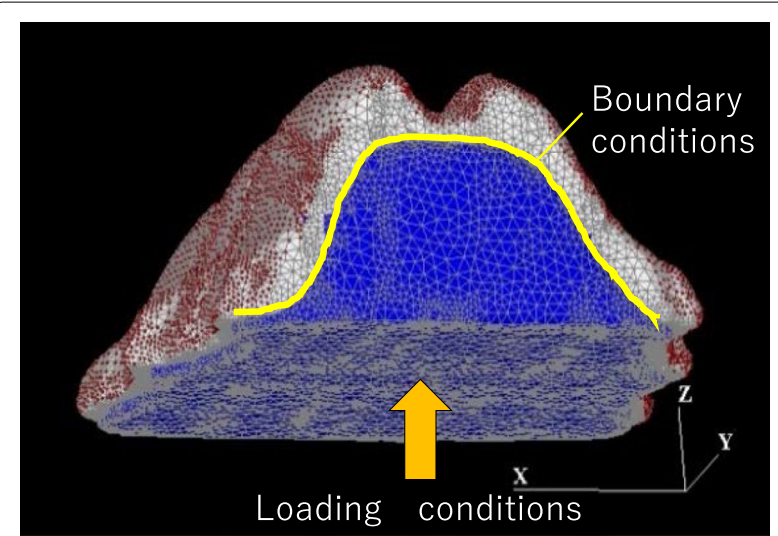

Fig. 3 Loading conditions and Boundary conditions

(3) Restraint conditions

The uppermost surface of the palatal mucosa model was assumed to adhere to the maxillary bone, and the model was fully constrained [10].

(4) Boundary conditions

The boundary conditions in the pseudopalatal plate model and palatal mucosa model were considered as the adhesion conditions [10] (Fig. 3).

\section{Analysis target}

In the palatal mucosa model, the volume of the range within which von Mises stress was generated at each borderline or higher was calculated, and the results were compared between each condition, with and without relief.

\section{Results}

\section{Comparison of von Mises stress generated in relief} and no-relief palatal mucosa models

The distributions of von Mises stress generated in the relief and no-relief palatal mucosa models are shown in Fig. 4.

In this study, von Mises stress was used instead of principal stress because the objective was to know the stress distributed throughout the palatal mucosa.

In the relief model with borderline at $0.04 \mathrm{MPa}$ or higher and $0.06 \mathrm{MPa}$ or higher, the stress distribution was higher toward the front of the mid-palatal area than in the no-relief model. In the relief model with borderline at 0.08 or higher, 0.10 or higher, and $0.14 \mathrm{MPa}$ or higher, no marked changes were found in comparison with the no-relief model. In addition, in the mid-palatal relief model, stress distribution was at the margin of the relief range and at both margins of the palatal plate.

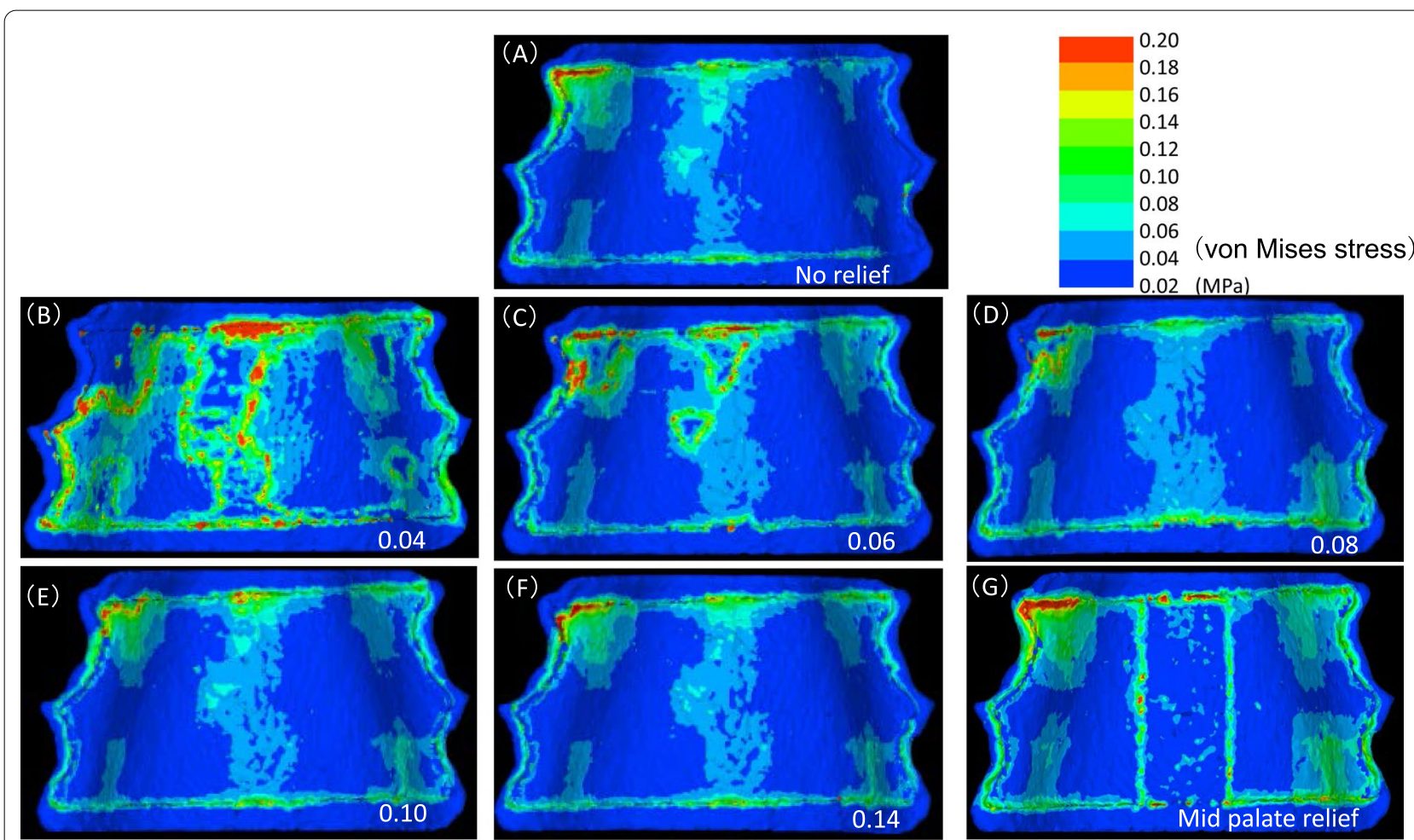

Fig. 4 Distribution map of von Mises stress. A No relief; B relief more than $0.04 \mathrm{MPa}$; $\mathbf{C}$ relief more than $0.06 \mathrm{MPa}$; $\mathbf{D}$ relief more than $0.08 \mathrm{MPa}$; $\mathbf{E}$ relief more than $0.10 \mathrm{MPa} ; \mathbf{F}$ relief more than $0.14 \mathrm{MPa} ; \mathbf{G}$ mid-palate relief 


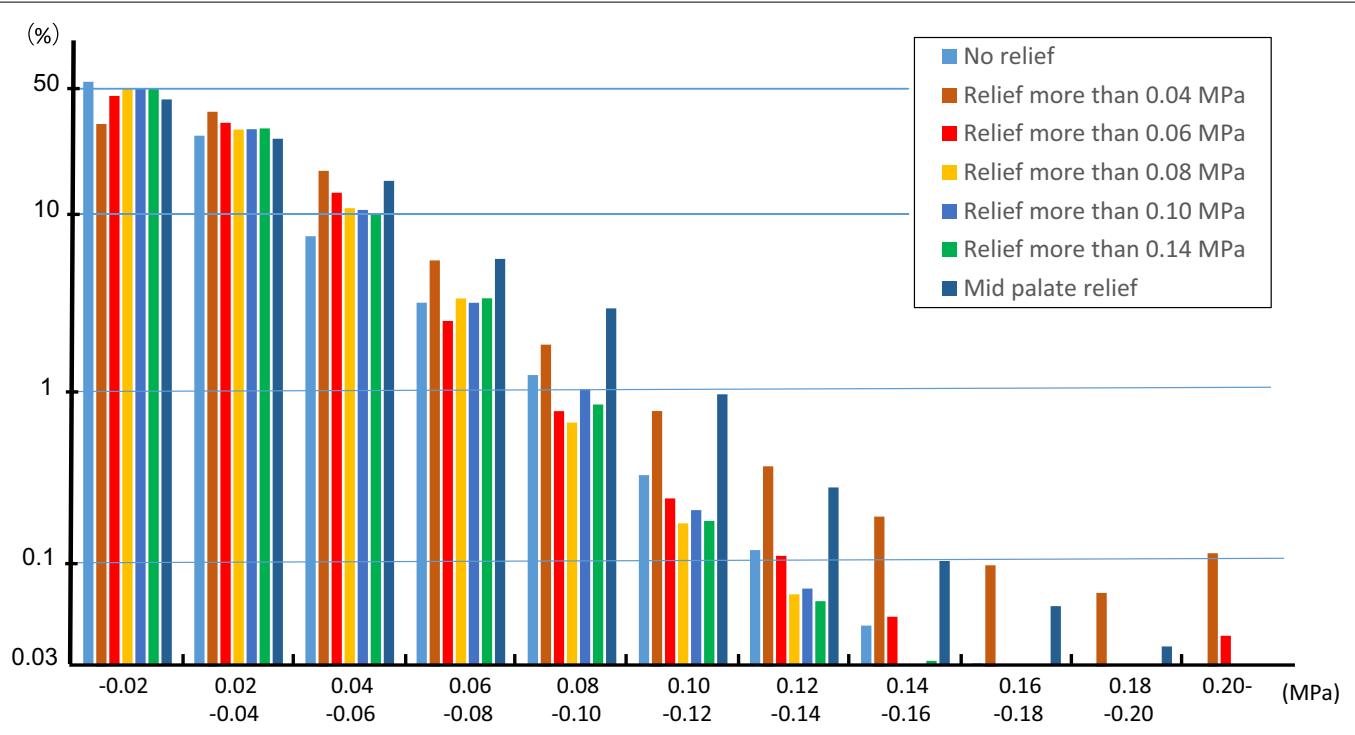

Fig. 5 Volume ratio of stress distribution at each stress value

\section{Distribution volume ratios for each stress values}

The distribution volume ratios for each stress value on the palatal mucosa are shown in Fig. 5. With a borderline of $0.04 \mathrm{MPa}$ or higher and $0.06 \mathrm{MPa}$ or higher, the relief model was found to increase the distribution volume of stress at $0.20 \mathrm{MPa}$ or higher. In the relief model with a borderline of $0.08 \mathrm{MPa}$ or higher and $0.10 \mathrm{MPa}$ or higher, the stress distribution was at $0.14 \mathrm{MPa}$ or lower. In the relief model with a borderline of $0.14 \mathrm{MPa}$ or higher, the stress distribution at $0.08 \mathrm{MPa}$ or higher decreased, and stress at $0.06 \mathrm{MPa}$ or lower increased. In the midpalatal relief model, the distribution volume of stress at $0.04 \mathrm{MPa}$ or higher increased in comparison with that in the no-relief model. In addition, a comparison of the relief models with each borderline showed maximum increases in stress distribution volume between 0.06 and $0.12 \mathrm{MPa}$.

\section{Distribution volume ratios for each stress value in the relief model}

Figure 6 shows the distribution volumes in the relief model relative to the situation when the distribution volume for each stress value in the no-relief model was considered to be $100 \%$. In the relief model with a borderline of $0.04 \mathrm{MPa}$ or higher, the distribution volume at which a high stress of $0.20 \mathrm{MPa}$ or higher was generated was approximately $800 \%$ of that with the no-relief model, and in the relief model with a borderline of $0.06 \mathrm{MPa}$ or higher, the respective ratio was approximately $280 \%$. On the other hand, the relief models with borderline of $0.08 \mathrm{MPa}$ or higher, $0.10 \mathrm{MPa}$ or higher, and $0.14 \mathrm{MPa}$ or higher were less than $100 \%$, and among them, the relief models with values of $0.14 \mathrm{MPa}$ or higher were approximately $60 \%$. In the mid-palatal relief model, the distribution volume at which a stress of $0.20 \mathrm{MPa}$ or higher was generated was $180 \%$ of that in the relief model.

\section{Discussion}

\section{Subject and region of interest}

The subject in this study was dentate, with healthy teeth and was selected as a reference to obtain useful data regarding the palatal mucosa of dentate patients before evaluating the denture-supporting mucosa of edentulous patients. Because this study covered only the mean palatal configuration of a single subject, it was confined to various aspects of the intraoral status of that subject, including the presence or absence of palatal tori, and palatal shape, with the primary focus being the development of analysis methods. In the future, it is necessary to investigate the differences due to palatal shape [9].

In addition, the simulated relief model is currently used in practice for creating pseudopalatal plates that reflect a relief based on each borderline in CAD/CAM that was output from the STL data. These plates were combined with a simultaneous measurement device [9] and were used to verify the simulated validity with subjects.

\section{Setting the borderline}

In this study, the borderline for the simulation was set between 0.02 , which was the level of stress generated in the palatal mucosa model, and $0.20 \mathrm{MPa}$, and the stress distribution was analyzed. It is difficult to set stress 


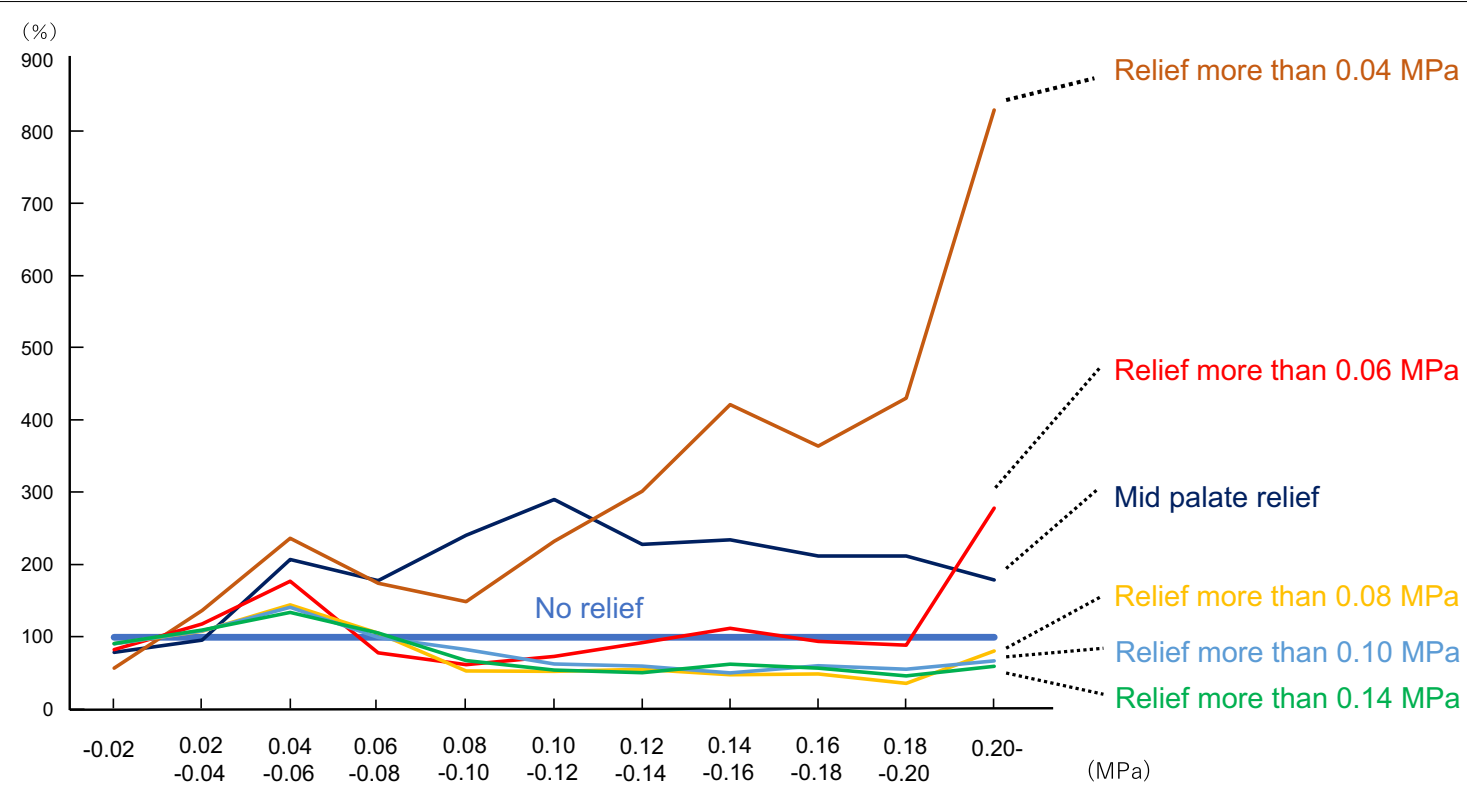

Fig. 6 Comparison of relief model and no-relief model

values for the onset of pain, but pain is thought to occur readily at relatively high stress values.

\section{Finite element analysis methods and analysis models}

Analysis based on finite elements enables the partitioning of elements in the model, detailed setting of loading conditions and physical properties, and accurate simulation based on the introduction of temporal elements to the linear analysis and dynamic analysis. However, if analysis is performed with more detailed conditions set, considerable time is required. Therefore, for commercial use, in order to have a general appreciation of the entire tendency at the initial stages of structural design, sometimes only a first-order analysis is performed, that is, an approximate analysis, with the details simplified [14]. In the present study, the stress distribution was analyzed using an FEA model, and a simulation was performed for the stress distribution on the denture-supporting mucosa when relief was applied to ranges of the borderline and higher.

\section{Effects of relief on the palatal mucosa}

In this study, the stress values increased by approximately $800 \%$ in the relief model with a borderline of $0.04 \mathrm{MPa}$ or higher and by approximately $180 \%$ in the median relief model, compared with that in the norelief model (Fig. 6). This suggests that excessive relief (e.g., relief model with a borderline of $0.04 \mathrm{MPa}$ or higher) or standard relief (e.g., mid-palatal relief model) reduces the support area of the plates outside the relief range-this, in turn, causes excessive localized stress, which may lead to pain. On the other hand, in the relief model with a borderline of $0.14 \mathrm{MPa}$ or higher, the high stress value was less than $100 \%$ compared with the norelief model, and the stress was evenly distributed over the entire palatal mucosa. If relief can be applied locally, restricted to the sites of high stress generation, the supportive strength of the plate can probably be increased by making the stress consistent. In summary, the findings of this study suggest that relief applied based on the dentist's subjective judgment and experience is not necessarily effective.

In this study, an FEA model was created using the elastic modulus of the palatal mucosa, mucosal thickness, and actual bite force measured in the oral cavity in previous studies [9], and the bite force and stress were analyzed in relation to the bite force at the time of pain generation; thus, it is necessary to consider strain in future studies. Additionally, we plan to validate the simulation by applying the structural optimization technology to change the stress value and the effect of repeated relief, and by using CAD/CAM to fabricate the pseudopalatal plate model created in this study and measuring the bite force during pain generation in an actual mouth.

\section{Conclusions}

In this study, the high-stress distribution volume of the mid-palatal relief model increased in comparison with that of the no-relief model. On the other hand, in relief 
models with a borderline of $0.14 \mathrm{MPa}$ or higher, stress was evenly distributed over the entire palatal mucosa. This suggests that the supportive strength of plates can be increased by selectively applying optimal relief rather than standard relief.

\section{Abbreviations}

3D: Three-dimensional; FEA: Finite element analysis.

\section{Acknowledgements}

The authors would like to thank the staff of the Department of Geriatric Dentistry, Showa University.

\section{Authors' contributions}

TM contributed to the study design/conception, material preparation, execution of the three-dimensional finite element models, original draft writing and revision. YS provided supervision, corrected the manuscript, and reviewed the progress of the study. OS contributed to the study design/conception and material preparation. JF and Al interpreted the results and revised the manuscript. TO contributed to the draft preparation and execution of the three-dimensional finite element models. All authors read and approved the final manuscript.

\section{Funding}

This work was supported by JSPS KAKENHI Grant Number 16K20513.

\section{Availability of data and materials}

Data may be made available from the corresponding author on reasonable request.

\section{Declarations}

Ethics approval and consent to participate

The study was conducted in accordance with the principles of the Declaration of Helsinki. The informed consent form was approved by the Ethics Committee of Showa University (approval number 2014-036).

\section{Consent for publication}

Not applicable.

\section{Competing interests}

The authors declare that they have no competing interests.

Received: 21 September 2021 Accepted: 30 November 2021

Published online: 20 December 2021

\section{References}

1. Sato Y, et al. Estimation of denture patients' absolute number in elderly from survey of dental diseases and vital statistics. Jpn J Dent Pract Admin. 2014;49:162-7 (in Japanese).

2. Tanaka S. Digital dentistry changes prosthodontics. J Showa Med Assoc. 2015;75:38-45 (in Japanese).

3. Hiraoka H. Clinical practice of the zirconia denture base. Int J Dent Technol. 2015;43:408-21.

4. Academy of denture prosthetics: glossary of prosthodontic terms. J Prosthet Dent. 2005;94:10-81.

5. Masatoshi I, Misao K, Sayumi I, et al. Pressure dynamics in the trays caused by differences of the various impression materials and thickness of the relief in the maxillary edentulous model. J Prosthodont Res. 2016;60:123-30.

6. Takeuchi S, Sato Y, Sato Y, et al. Measurements of viscoelasticity of oral mucosa -establishing a simultaneous measurement method for load and change of the mucosa thickness. Ann Jpn Prosthodont Soc. 2010;2:70-7 (in Japanese).
7. Isobe A, Sato Y, Kitagawa N, Shimodaira O, Hara S, Takeuchi S. The influence of denture supporting tissue properties on pressure-pain threshold -measurement in dentate subjects. J Prosthodont Res. 2013;57:275-83.

8. Kotani Y. Relationship between palatal mucosa properties and pressurepain threshold in young dentulous and elderly edentulous subjects. J J Gerodont. 2015;30:68-79.

9. Tanaka S, Sato Y, Kitagawa N, et al. Effect of relief at the median palatal plate on denture-supporting ability. Int J Prosthodont Endod. 2017;7:117-23.

10. Omori T, Sato Y, Kitagawa N, et al. Effects of palatal plate loading on mucosa development in three-dimensional finite element model. Int J Prosthodont Endod. 2020;10:50-6.

11. Ishinabe S. Mucosal thickness of the denture foundation under occlusal force. J Jpn Prosthodont Soc. 1991;35:111-24 (in Japanese).

12. Sato $Y$, Abe $Y$, Okane $H$, Tsuga K. Finite element analysis of stress relaxation in soft denture liner. J Oral Rehabil. 2000;27:660-3.

13. Kanbara R, Nakamura Y, Ochiai KT, Kawai T, Tanaka Y. Three-dimensional finite element stress analysis: the technique and methodology of nonlinear property simulation and soft tissue loading behavior for different partial denture designs. Dent Mater J. 2012;31:297-308.

14. Omori M, Sato Y, Kitagawa N, Shimura Y, Ito M. A biomechanical investigation of mandibular molar implants: reproducibility and validity of a finite element analysis model. Int J Implant Dent. 2015;1:10.

\section{Publisher's Note}

Springer Nature remains neutral with regard to jurisdictional claims in published maps and institutional affiliations.
Ready to submit your research? Choose BMC and benefit from:

- fast, convenient online submission

- thorough peer review by experienced researchers in your field

- rapid publication on acceptance

- support for research data, including large and complex data types

- gold Open Access which fosters wider collaboration and increased citations

- maximum visibility for your research: over 100M website views per year

At BMC, research is always in progress.

Learn more biomedcentral.com/submissions 